\title{
Post-traumatic tremor in head injured children
}

\author{
S L J Johnson, D M B Hall
}

\begin{abstract}
In a survey of 289 severely head injured children the prevalence of significant tremor was estimated to be at least $45 \%$. The tremor appeared at any time within the first 18 months after injury and in at least half the cases it subsequently subsided spontaneously. The implications of these findings are to question the mechanism of recovery and suggest that controlled trials of the treatment needed.
\end{abstract}

Post-traumatic tremor is a recognised complication of head injury in children ${ }^{1}$ but little is known about its prevalence and natural history. We had observed a significant upper limb tremor in five of 17 consecutive admissions to a children's head injury rehabilitation unit, between three and 18 months after the injury. In three of the five it subsequently disappeared spontaneously. These observations prompted the present study which was undertaken to determine the prevalence and evolution of posttraumatic tremor.

\section{Method}

The study was carried out by a postal survey of subjects chosen from the University of York's Social Policy Research Unit (SPRU) computerised databank of children registered with the Family Fund. ${ }^{2}$ About 814 head injured children are known to the fund.

A sample of 289 children stratified by age was selected, so that there were approximately equal numbers of children in each age group, except for the younger age group as there were fewer younger children on the register. The age stratification is shown in table 1 .

A questionnaire was devised and was sent by the Family Fund to the parents of each child. To determine the severity of the head injury, questions were asked about loss of consciousness at the time of the injury, the duration of coma, and whether assisted ventilation was required. Movement disorder and disability were assessed with respect to mobility, self help skills and

Grosvenor Hospital, Sydney, Australia $S$ L J Johnson

Clare House,

St George's Hospital, London SW17 OQT D M B Hall

Correspondence to: Dr Hall.

Accepted 15 September 1991

Table 1 Age stratification of the 289 children

\begin{tabular}{lc}
\hline Year of birth & No of children \\
\hline $1984-88$ & 31 \\
$1979-83$ & 65 \\
$1974-78$ & 64 \\
$1969-73$ & 65 \\
$1964-68$ & 64 \\
Total & 289 \\
\hline
\end{tabular}

communication, using a modification of a method for recording central motor deficit. ${ }^{3}$ Permission was requested for the investigator to examine the fund's file for each child, so that as far as possible the parents' replies could be validated. Ethics committee approval was obtained for the survey.

\section{Results}

There were 169 responses obtained in the first three months after distributing the questionnaires. Reminders were sent to all the nonresponders. A further 30 questionnaires were subsequently received, giving a total of 199 responses (response rate of $69 \%$ ). The age distribution of the responders is shown in table 2 .

As we had anticipated, some parents confused seizures with tremor and these cases are excluded. There were 131 children who we judged to have had a tremor at some time, in the 199 responders $(66 \%)$. It was possible to examine files held by the Family Fund in about $60 \%$ of these 131 cases and in all of these the presence of tremor as reported by the parents was confirmed in medical notes. Files were examined only if permission had been given by the parents.

In the 30 cases where questionnaires were received after the reminder, none of the children had tremor. Assuming that parents were more likely to respond if their child did have tremor and that tremor may not have been present in any of the remaining 101 non-responders, the prevalence of tremor in the group of 289 cases is $45 \%$.

The severity of the injuries suffered by these children is illustrated in table 3 . There was no apparent correlation between severity of the head injury and the time of onset of the tremor. In 131 children who had tremor, the onset was

Table 2 Age at injury of the children in 199 responses

\begin{tabular}{ll}
\hline Age (years) & No of children \\
\hline $0-5$ & 79 \\
$>5-10$ & 66 \\
$>10-15$ & 43 \\
Age could not be recalled & 11
\end{tabular}

Table 3 Severity of injuries in 199 responders

\begin{tabular}{lc}
\hline $\begin{array}{l}\text { Injury or } \\
\text { disability }\end{array}$ & $\begin{array}{l}\text { No (\%) of } \\
\text { children }\end{array}$ \\
\hline Coma duration >14 days & $143(72)$ \\
Required intensive care & $192(96)$ \\
Required assisted ventilation & $162(81)$ \\
Wheelchair dependent & $35(18)$ \\
Totally dependent & $28(14)$ \\
Communication difficulties & $120(60)$ \\
\hline
\end{tabular}


within two months of the accident in 64 (49\%), between two and 12 months in $52(40 \%)$, and in the second year in three $(2 \cdot 3 \%)$. No information was available in 12 cases. In $54 \%$ of cases the tremor subsided spontaneously over time, it remained unchanged in $31 \%$, and it progressively worsened in $5 \%$ for a period of up to three years after the injury.

\section{Discussion}

The Family Fund exists to help families of children who are severely disabled, so that it was not surprising to find that most of the subjects in the survey were in this category. However, tremor is probably associated with extensive brain injury. Each of the five patients with tremor in our unit lost consciousness at the time of the accident, remained in coma for a minimum period of three weeks and had residual neurological deficits. None of these patients were on anticonvulsant medications, which could account for tremor as a side effect.

In most children the tremor occurred when a static posture was maintained and was exaggerated by activity and anxiety. It was not observed at rest. The tremor was of large amplitude and low frequency as distinct from the high frequency, low amplitude tremor of anxiety.

Tremor seems to be associated with midbrain lesions. In 1904 Holmes reported on two patients with midbrain glioma at necropsy, who had extremity tremor before their death. Since then there have been further reports of extremity tremor in patients with midbrain lesions. Maki et al described four head injured children with basal ganglia infarction visible on the computed tomogram, who developed extremity tremor after their injury. ${ }^{4}$ Four of the five children in our unit had evidence of midbrain trauma on computed tomography. (For details of their neuroradiology, see table 4.)

Tremor can be extremely incapacitating and these children may benefit from treatment. Propranolol $^{5}$ and dopamine agonists like bromocriptine and stereotactic neurosurgery ${ }^{6}$ have been used to treat tremor. However, our
Table 4 Neuroradiological details of four children

\begin{tabular}{lll}
\hline $\begin{array}{l}\text { Patient } \\
\text { No }\end{array}$ & $\begin{array}{l}\text { Sex/age } \\
\text { (years) }\end{array}$ & $\begin{array}{l}\text { Results of computed } \\
\text { tomography }\end{array}$ \\
\hline 1 & $\mathrm{M} / 12$ & $\begin{array}{l}\text { Left parietal and right occipital cerebral } \\
\text { contusion, small haemorrhages in the } \\
\text { corpus callosum and tectum of the } \\
\text { midbrain }\end{array}$ \\
2 & $\mathrm{M} / 13$ & $\begin{array}{l}\text { Compound contusion of the cerebral } \\
\text { hemispheres, right thalamic contusion, } \\
\text { pontine contusion, intraventricular } \\
\text { haemorrhage, and cerebral oedema } \\
3\end{array}$ \\
4 & $\mathrm{M} / 10$ & $\begin{array}{l}\text { Multiple small haemorrhages in the dorsal } \\
\text { pons and the tectal plate of the midbrain }\end{array}$ \\
& $\mathrm{M} / 9$ & $\begin{array}{c}\text { Small haematoma of the midbrain, right } \\
\text { ventricular haemorrhage, and cerebral } \\
\text { oedema }\end{array}$ \\
\hline
\end{tabular}

observation that tremor subsided spontaneously in three of the patients admitted to our unit and in more than $50 \%$ of the cases in the survey is supported by other reports $^{6}$; this has two important implications. Firstly, it raises interesting questions about the mechanisms of recovery and repair in the injured brain and secondly, it suggests that carefully controlled trials of treatment regimens are essential.

It would of course be unwise to draw detailed conclusions from a retrospective questionnaire survey, but our study does confirm that tremor is a common problem in head injured children and contributes significantly to the overall level of disability. There is a need for a prospective study on the incidence and natural history of post-traumatic tremor, and the effectiveness of treatment.

We thank the staff at SPRU, the Family Fund, and the parent who participated; without them this study would not have been possible.

Obeso JA, Narbona J. Post-traumatic tremor and myoclonic jerking. F Neurol Neurosurg Psychiatry 1983;46:788.

2 Bradshaw IR, Lawton D. 75000 severely disabled children. Dev Med Child Neurol 1985;27:25-32.

Stewart A. Standard recording of central motor deficit. Dev Med Child Neurol 1989;31:121-9.

4 Maki Y, Akimoto H, Enomoto T. Injuries of basal ganglia following head trauma in children. Child's Brain 1980;7 113-23.

5 Ellison PH. Propanolol for severe post head injury action tremor. Neurology 1978;28:197-9.

6 Andrew J, Fowler C, Harrison M. Tremor after head injury and its treatment by stereotaxic surgery. $\mathcal{F}$ Neurol Neurosurg and its treatment by stereota
Psychiatry 1982;45:815-9. 